\title{
CONFLICTIVITAT I RUPTURA EN EL. MATRIMONI
}

\author{
Emili M. Boix i Selva \\ amb la collaboració de \\ Joan Anton Martínez Manso \\ (Universitat de Barcelona)
}

Es tracta de la intensa i generalitzada crisi del matrimoni, de profunda i àmplia repercussió social, basant-se en documentats estudis i fidedignes estadístiques. Es desenvolupa una tipologia de les situacions d'exclusió, tensió, confictivitat i ruptura que es donen en relació amb el mattimoni. Sintetitzada, és la segứent: a) unions sense lligam juríaic; $b$ ) conflictivitat en el si del matrimoni; c) doblatge entre la vida conjugal i unes telacions sexuals extramatrimonials; d) separacions merament de fet o a través d'un conveni; e) separació judicial o administrativa, mantenint-se el vincle; $f$ ) nova convivència fixa amb tercera persona; $g$ ) assoliment d'una sentència de divorci vincular; b) obtenció d'una resolució judicial que declarí nul el matrimoni o d'una dispensa que el deixi sense efecte. S'inclou el resuitat d'una anàlisi sociologica efectuada sobre una mostra de les causes de separació conjugal introduides al Tribunal Eclesiàstic de Barcelona, en el període 1968-1974. Es destaca la importància, a part de consideracions jurídiques, de l'existència d'un veritable amor psíquic i sexual, d'una compenetració intellectual $i$ afectiva, que faci veritablement estable la unió matrimonial i que permeti de superar les influències derivades, en bona part, de la massificació, del materialisme egoista i del consumisme, existents en la societat capitalista i que porten a la tensió, a la confictivitat i a la ruptura matrimonial. 


\section{Canvi en la concepció del matrimoni}

El matrimoni, mitjà de la més profunda i completa unió psíquica, física i social i font de vida i de goig, entre els éssers humans, és també l'origen i la base de fortes tensions i durs trencaments.

En referir-nos al matrimoni en el present treball, alludim, en general, a la forma d'unió conjugal establerta en els països que amb expressió convencional, i certament molt discutible, anomenem occidentais i que es fonamenta, en principi, en una concepció cristiana.

En el dit àmbit, va perdent el seu caràcter d'institució, amb els seus objectius i funcions fixats $i$ regulats. Tendeix a ésser considerat en la realitat social, encara que no sigui un fet jurídic en el seu origen, en el seu contingut intrínsec $\mathrm{i}$ formal, com un acord basat quasi únicament en una interacció personal, de recíproca acceptació i estimació, projectada vers un mutu desenvolupament i una joiosa satisfacció.

Ja no tespon, com molt sovint succeila, a la voluntat més o menys in teressada dels pares, Iligada freqüentment a criteris religiosos, d'estructura econòmica, de prestigi social i àdhuc de partidisme polític.

Fent referència a aquest fet, que cada dia va quedant més limitat a un record del passat, Michel expressa: «L'estructura de la família tradicio nal, els papers i posicions dels seus membres, les idees, els valors, els mites relatius a la vida familiar, eren principalment consequència de la combinació d'una estructura econòmica en un marc rural arcaic i d'una estructura jurídica donada que establia una forma determinada de transmissió de la propietat. La combinació de tots aquests elements estructurava la família tradicional. $\rangle^{1}$

Així mateix s'han superat, en bona part, els matrimonis que eren efecte dels citats mòbils tradicionals, tinguts en compte pels mateixos contraients.

1. Citat per Isidoro Alonso Hinojal en La crisis de la institución matrimonial (Barcelona: Salvat, 1974), p. 35. 
Actualment, tenen un paper més important els factors de tipus psicològic, sexual, ideològic i social. En aquest sentit, Amando de Miguel ba escrit: «L'ajustament i la realització sexual depenen en un $50 \%$ de trobar la persona amb la qual ajustar-se o realitzar-se. $\rangle^{2}$

Hom sosté que la unió matrimonial per tenir un suport de fermesa i de continuiltat s'ha de basar en una mútua, recíproca, autèntica i amorosa atracció sexual i psíquica, en definitiva en una profunda dependència afectivo-sexual; en unes actituds personals que possibilitin una coordinació $i$ una harmonia superadora, de contrastos $i$ possibles contradiccions; en una fonamental coincidència, a desgrat de naturals i obligades diferències, en la concepció del món, de la vida $i$ de la societat $i$, en $\mathrm{fi}_{\text {, en }}$ una certa similitud en l'acceptació de normes vitais i socials de comportament.

Therese Benedik manifesta: «L'amor heterosexual és l'atracció entre un home $i$ una dona que han assolit un nivell específic de maduració individual $i$ que es necessiten mútuament per a completar-la.» ${ }^{3}$

En definitiva, es tendeix al fet que el matrimoni sigui una relació interpersonal intima que superi, dintre les limitacions que la naturalesa imposa, l'aillament i la solitud a la qual tots els homes estem forçats i faciliti la formació i la continuïtat d'una «íntima comunitat de vida i d'amor», com ha proclamat l'Església catòlica en un dels textos del Concili Vaticà $\mathrm{II}^{4}$

En el sentit indicat, Hunt ha escrit: «Doncs, si bé el matrimoni ja no té el suport estructural de la religió, la comunitat, la llei o la necessitat pràctica, avui existeix un altre factor que fa de l'exclusivitat o de l'aparença d'exclusivitat quelcom molt important; em refereixo a la soledat i l'aillament de la vida moderna, que creen en l'home $i$ en la dona una fonda necessitat de pertànyer a algú $i$ de tenir amb aquest algú un llaç emocional. ${ }^{5}$

2. Amando de Miguel, Sexo, mujer y natalidad en España (Madrid: Cuadernos para el Diálogo, 1974), p. 14.

3. En From, Horkheimer, Parsons i altres, La familia (Barcelona: Península, 1974), p. 154.

4. Concili Vaticà. Constitucions. Decrets. Declaracions, Constitució Pastoral sobre l'església en el món d'avui (Madrid: BAC, MCMLXVII), p. 315.

5. Morton Hunt, La conducta sexual, boy (Barcelona: EDHASA/SUDAMERICANA, 1978), p. 287. 


\section{Tensions matrimonials}

El fet de les discordances força generalitzades en el si dels matrimonis és de fàcil constatació. Creiem que, en l'àmbit del nostre país, una part es desenvolupen en una adequada harmonia. Una altra part, es toleren, s'aguanten i se suporten per la tutina, els convencionalismes socials, les conviccions religioses i morals, les exigències jurídiques, els interessos materials o per tenir uns fills comuns que salven o dissimulen, en certa manexa, la manca d'uns vincles més sòlids i profunds. Aquestes parelles tenen tan sols una aparença de normalitat. En un tercer sector, s'ba produitt entre els cònjuges un fort trencament en els sentiments, en les idees $i$ en els comportaments, que ha tingut com a consequiència la ruptura de la vida comuna.

Són nombrosos els factors que porten a la dissociació matrimonial. Bàsicament, són els contratis dels elements que hem indicat com a constitutius d'una ferma, equilibrada i continuada relació interpersonal. Llavors la desconfiança, la contradicció, la inseguretat, la desesperació, el conflicte i la lluita, en les seves diferents formes $i$ matisos ocupen el lloc de l'entesa $i$ la cooperació que abans es donaven. La intimitat i la continuïtat, psíquica, sexual, intellectual, emotiva, vital, creadora i esperançadora, s'han perdut.

Això concretament té com a efecte l'existència de tensions, incidents $i$ violències morals $i$ fins fúsiques $i$ que entrin en joc terceres persones -cercades, trobades o provocades- - que trenquen la unitat i l'exclusivitat matrimonial. No es tracta de les crisis, que es donen en tots els matrimonis, sinó quelcom que normalment és definitiu i insuperable. Abans es do. naven certes actituds de resignació que actualment són excepcionals.

\section{Tipologia de les crisis en el matrimoni}

a) Unions establertes amb una certa permanència sense vincle jurídic.

b) Confictivitat freqüent en la convivència entre els esposos que, a desgrat de tot, continua.

c) Doblatge de vida, consistent a conservar aparentment la normalitat matrimonial, per una banda, i per altra, incórrer en infidelitats accidentals o en amistançaments d'una certa permanència.

d) Ruptura profunda de la vida conjugal, amb la corresponent separació de fet, sense cap formalitat, mitjançant un conveni privat o protocolitzat davant de notari. 
e) Assoliment de la separació conjugal a través d'un procediment sumari o administratiu o a consequiència d'un procés contenciós, sense possibilitat d'un nou enllaç que pugui tenir validesa jurídica.

f) Nova convivència, a desgrat del manteniment del vincle jurídic, amb una altra persona diferent d'aquella amb la qual s'ha contret matrimoni.

g) Assoliment d'una resolució judicial de divorci vincular amb dret a un nou matrimoni.

b) Obtenció d'una sentència judicial en la qual es declara nulla la unió matrimonial o d'una dispensa que deixi sense efecte el matrimoni. En ambdós casos es reconeix l'estat de solteria $\mathrm{i}$, per tant, la possibilitat de contraute un nou enllaç.

a) Unions establertes amb una certa permanència sense vincle jurídic. Responen a la concepció que la unió entre home i dona és quelcom de caràcter privat, extraordinàriament íntin, essent per tant matèria en la qual el poder públic no té cap justificació per intervenir-hi. El fonament de l'enllaç purament personal es basa en l'amor i l'atractiu mutus i que ha de durar fins que aquests elements es mantinguin. Els seus antecedents es troben, en certa manera, en el matrimoni «a prova» o «d'assaig» admès en diversos països.

La societat actual tolera aquest tipus de relació més o menys permanent, estesa en molts indrets, quan es tracta especialment de persones joves, que estan units per un amor recíproc i que, en principi, no es volen Iligar d'una forma permanent. Engels considera «que el matrimoni és moral únicarnent quan es basa en "l'amor compartit" i que deixa d'ésser-ho quan l'estima desapareix». ${ }^{6}$

Es pot donar un exponent de l'actitud alludida mantinguda per molts joves sobre la unió conjugal establerta amb una certa permanència, sense vincle jurídic.

Pot trobar-se en el resultat de la investigació sociològica que es portà a terme a la Facultat de Cìncies Econòmiques i Empresarials de la Universitat de Barcelona, sota la direcció del sotascrit i de la professora Anna Alabart, en el curs 1975-1976, sobre «El matrimoni i les relacions familiars».

S'inclogué la següient pregunta: «Si creus que el matrimoni és adequat a les necessitats que la societat actual té plantejades, ¿quines creus que són les possibilitats que podrien ésser idònies: a) parella amb unió

6. Engeis, El origen de la familia, la propiedad privada y el Estado (Madrid: Ayriso, 1976), p. 23. 
Iliure, sense compromís de duració (poc estable); $b$ ) parella amb unió liiure, molt estable; $c$ ) que no existeixi parella; $d$ ) altres possibilitats? 》

EI $21 \%$ contestaren: «parella poc estable»; el $16 \%$ «que no existeixi parella» i l'11 \% «altres possibilitats». Entre aquests darrers, l'apuntada amb major frequiència fou «la comuna». En total, el $48 \%$ s'oposaren a la parella estable.

El qüestionari havia estat distribüt de la següent manera: 384 foren repartits entre els alumnes de primer curs (general i empresa). Això suposava una mostra del $12 \%$ sobre el total d'alumnes matriculats en el curs.

123 es repartiren entre els alumnes de cinquè curs. Equivalia a una mostra del $50 \%$ dels alumnes matriculats.

La mostra, evidentment, era representativa.

Els qüestionaris recollits foren: 244 entre els de primet curs i 123 entre els de cinquè.

En l'estudi efectuat entre els estudiants del Districte Universitari de Salamanca (Universitat Pontifícia i Universitat Estatal), a la pregunta de «Si la millor manera de conviure dues persones de diferent sexe és el matrimoni», les respostes foren les seguients: dones, en desacord el $39 \%$ i molt en desacord el $20 \%$; en els homes, en desacord el $36 \%$ i molt en desacord el $18 \%{ }^{7} \mathrm{El}$ conjunt d'estudiants eta de 14.210. La mostra es va fer sobre 990 persones, amb una representativitat del $7 \%$. Es van rebre 702 respostes, que representaven el $71 \%$ dels qütestionaris distribuits.

b) Conflictivitat frequient en la convivència entre els esposos, que a desgrat de tot, continua. Es van fent més freqüents i més esteses les dificultats i els desacords en el si dels matrimonis.

La incompatibilitat de temperaments, les diferències d'edat, els contrastos en els nivells culturals i socials, les dificultats econòmiques, les discordances ideològiques, la influència de terceres persones i en un grau molt acusat els desajustaments sexuals, entre altres que hi cabria citat, produeixen fortes tensions que fan difícil i dolorosa la convivència entre els esposos. Per raons religioses, ètiques, convencionals, pel temot a les complicacions d'un litigi judicial o pel que es considera el bé dels fills, es continua convivint. En aquests casos és impossible trobar estadístiques que precisin el nombre, encara que sigui aproximat, de matrimonis afectats.

7. Manuel Gutiérrez Calvo, Sexualidad de los universitarios. Conducta sexual relacionada con variables psicológicas, sociolbgicas y actitudes (Salamanca: Estudiantes y Profesionales de Psicología Asociados, 1978), p. 47. 
Persones dedicades a aquestes qüestions - psicòlegs, sociòlegs, advocats, sexòlegs, sacerdots, etcètera-, poden parlar de situacions en què es troben del tipus indicat en les seves investigacions i consultoris. Per altra banda, sha de tenir en compte que la major part de matrimonis amb tensions, dissimulen les circumstàncies doloroses en què viuen $i$, per tant, no poden ésser objecte d'estudi.

c) Doblatge de vida, consistent a conservar aparentment la normalitat matrimonial, per una banda, $i$ per l'altra, incorrer en infidelitats accidentals o en amistançaments d'una certa permanència. El fet pot respondre a moltes causes. Però en general és un exponent d'insatisfacció d'un o d'ambdós cònjuges provocada conscientment o inconscientment per algun d'ells o ésser consequiència de l'atractiu o interès lligat a una tercera persona. La situació es fa normalment dolotosa per part del cònjuge que no incorre en el fet, sigui causa o no, potser sense adonar-se'n, d'allò que ha succeït. En determinats països i en certs nivells de status el fet té una certa acceptació social.

Callejones, escriu: «Encara als nostres dies no és molt estrany trobar a Hispanoamèrica homes que mantenen dues families, l'una legal i l'altra extralegal. L'extraordinari d'aquest cas (que molts sociolegs, sobretot nordamericans, no acaben d'entendre) no es el fet de la duplicitat de famílies, sinó que la família legal sàpiga perfectament de l'existència de l'altra i l'accepta aparentment sense esforç $i$ fins sense gaire ressentiment. Haig de confessar que en principi això em sorprenia i em causava un cert escàndol, fins que un dia una d'aquestes esposes legals em donà la clau del misteri: "Jo sóc fidel al meu marit —em digué- $\mathrm{i}$ ell és un excellent proveïdor de la nostra família. Els meus fills seran els seus hereus i nosaltres tenim la posició social que ens correspon. L'altra és cosa molt diferent." ${ }^{8}$

En relació amb l'anteriorment expressat, es podrien donar moltes altres referències sobre l'altíssim percentatge de fills, fruit d'unions extramatrimonials en diversos països d'Hispanoamèrica. Segons Hernando, Amèrica és «un continent jove on hi ha milions i milions de nens abandonats perquè un altíssim percentatge són nascuts fora del matrimoni (les $2 / 3$ parts a la República Dominicana, la meitat a Veneçuela i el $70 \%$ a Panamà). Solament al Brasil es calcula que hi ha deu milions de nens abandonats».?

8. E. Callejones, Amor, sociedad y sexo en el matrimonio (Madrid: Norte, 1971), p. 31 .

9. Bernardino M. Hernando, Los pasillos de Pueblo (Madrid: PPC, 1979), p. 16. 
d) Ruptura profunda de la vida conjugal, amb la corresponent separació de fet, sense cap formalitat, mitjançant un conveni privat o protocolitzat davant de notari. L'increment de les separacions de fet sense cap formulisme és quelcom força estès com a conseqüència del trencament de la vida en comú que es considera impossible. El desconeixement dels diversos procediments jurídics, la comoditat i el menyspreu de formalitats oficials, el desig d'evitar altres tensions interpersonals, la desconfrança dels jutjats, l'estalvi de les possibles despeses, la necessitat de trobar un encartilament immediat a la situació i d'evitar un trencament definitzr, són factors que determinen la ruptura al marge dels tràmits judicials, de la convivència matrimonial i sense documentació i regulació de la problemàtica futura. Aquesta és l'actitud més cortent entre les persones pertanyents als nivells sòcio-econòmics i culturals més dèbilis. Això també es dóna com a tendència entre els matrimonis joves, de les diverses classes socials.

Altres vies per fer efectiva la sepatació es troben en un conveni escrit, purament privat o protocolitzat davant de notari. En aquests casos es preveuen i es fixen clàusules que regulin preferentment les qüestions relacionades amb la custòdia dels fills i el règim de visites i estades tempotals amb el cònjuge que no eis tingui normalment amb ell, determinació del que continuarà usant l'antic domicili conjugal, règim econòmic entre ambdós i els referexts a la llibertat sexual.

En una enquesta duta a terme a una mostra de 32 advocats «matrimonialistes» el qüestionari de la qual fou preparat per la Secció de Sociologia i Psicologia Jurídiques del Collegi d'Advocats de Barceiona, dóna la xifra de 3,6 separacions extrajudicials de cada 10 tractades en els seus bufets. ${ }^{10}$ En aquest mateix qüestionari i quan es tracta dels motius pels quals aconsellen les separacions de fet amb preferència a les separacions judicials es destaca en primer lloc el «desig d'evitar tensions interpersonals» seguit a força distància per «l'evitació de ruptura definitiva» $\mathrm{i}$ «cost del procés». També creiem interessant destacar en la mateixa enquesta que figuren en els primers llocs, com a motius personals per aquest tipus de separacions, el caràcter $\mathrm{i}$ el fet de no tenir fills.

Quant a la protocolització notarial, el $80 \%$ dels entrevistats opinen que el nombre d'aquestes no passa del $20 \%$. Finalment, els entrevistats destaquen majoritàriament que la instauració del divorci vincular i d'un criteri més obert en matèria de nullitats seria factor determinant per dis. minuir aquest tipus de separacions.

10. «32 abogados matrimonialistas contestan a un cuestionario sobre separaciones matrimoniales de hecho", Sociología y Psicologia jurídicas (Anuatio 1974), Ilustre Colegio de Abogados, p. 199. 
«Papers»: Revista de Sociologia

e) Assoliment de la separació conjugal a través d'un procediment sumari o administratiz o a conseqüència d'un procés contenciós sense pos sibilitat d'un nou enllac que pugui tenir validesa juridica. Aquest tipus de separació és acceptat per l'Església catòlica i també és regulat en diversos paisos al costat del divorci vincular. No admet la possibilitat d'un nou enllaç que pugui tenir validesa jurídica.

La legislació de l'Església, que actualment és objecte de reforma, fxa com a causes legítimes de separació de «llit, taula i habitació» les següents: l'adulteri, l'educació acatòlica dels fills per part d'un dels cònjuges, la vida de vituperi i ignomínia, el greu perill per a l'ànima o el cos, la desatenció de deures, les sevícies (mals tractes de paraula o obra), que facin la vida en comú massa difícil i «altres coses semblants».

En tots els països on no està previst el divorci vincular han augmentat molt aquesta mena de separacions. Limitant-nos a Espanya, podem incloure la següent relació on es palesa l'augment de causes introduides i les resolucions sobre elles en els 'Tribunals Eclesiàstics. ${ }^{11}$

\begin{tabular}{cccccc}
\hline Any & $\begin{array}{c}\text { Causes } \\
\text { introdüdes }\end{array}$ & Autoritzades & Denegades & $\begin{array}{c}\text { No arribaren } \\
\text { a terme }\end{array}$ & $\begin{array}{c}\text { Index de } \\
\text { creixement }\end{array}$ \\
\hline 1952 & 828 & 260 & 86 & 522 & 100 \\
1956 & 946 & 340 & 110 & 496 & 114 \\
1960 & 1.056 & 416 & 168 & 472 & 127 \\
1965 & 1.267 & 461 & 194 & 612 & 153 \\
1970 & 1.896 & 546 & 141 & 1.209 & 227 \\
1974 & 3.341 & 1.679 & 318 & 1.344 & 407 \\
\hline
\end{tabular}

11. José Ma. Díaz Mozaz, Datos sociológicos y estadísticos de la actual crisis matrimonial dins Curso de Derecho Matrimonial y Procesal Canónico, para profesionales del foro. Ponencias del IV Simposio de Miembros del Tribunal Eclesiástico (Salamanca: Universidad Pontificia, 1977), p. 21. 
Conflictivitat i ruptura en el matrimoni

Quant al Tribunal de Barcelona, podem donar les següents dades. ${ }^{12}$

a) Separacions judicials.

\begin{tabular}{cccc}
\hline Any & Introduïdes & Sentències & Arxivades \\
\hline 1960 & 260 & 125 & 76 \\
1961 & 285 & 104 & 80 \\
1962 & 299 & 87 & 56 \\
1963 & 274 & 184 & 85 \\
1964 & 283 & 245 & 134 \\
1965 & 335 & 208 & 121 \\
1966 & 361 & 242 & 156 \\
1967 & 352 & 142 & 118 \\
1968 & 345 & 193 & 85 \\
1969 & 384 & 207 & 131 \\
1970 & 496 & 209 & 138 \\
1971 & 544 & 231 & 99 \\
1972 & 621 & 289 & 162 \\
1973 & 689 & 322 & 91 \\
1974 & 773 & 401 & 207 \\
1975 & 972 & 514 & 268 \\
1976 & 1.163 & 681 & 314 \\
1977 & 1.307 & 759 & 369 \\
1978 & 1.663 & 937 & 290 \\
\hline
\end{tabular}

Prenent com a base 100 l'any 1960 , les causes iniciades han sofert, fins a l'any 1978, un increment del $638,4 \%$, i les sentències, el d'un $749,6 \%$.

b) Separacions sumàries o administratives.

\begin{tabular}{ccc}
\hline Any & Presentades & Concedides \\
\hline 1977 & 248 & 175 \\
1978 & 400 & 302 \\
\hline
\end{tabular}

12. Dades facilitades pel Tribunal Eclesiàstic de Barcelona. 
$\mathrm{Cal}$ fer notar que aquest tipus de tramitació, admès per l'Església $\mathrm{Ca}$ tòlica, si no és en els casos d'adulteri, no havia tingut aplicació a Espanya fins que, l'any 1977, a conseqüència d'un dectet de 29 de desembre de 1976, fou regulat a l'Arxidiòcesi de Barcelona.

Significa en Ia pràctica, tenint en compte els mateixos efectes legals que les separacions judicials, uns indubtables avantatges quant a agilitat, rapidesa $\mathrm{i}$ menys despeses, i sobretot evita dolorosos enfrontaments entre els cònjuges.

Influeixen en el fet de la intensificació de causes el procés d'industrialització i urbanització tan ligats amb els moviments migratoris cap a les grans ciutats; la secularització i l'extensió d'un concepte utilitari i còmode de la vida; la major independència i la promoció social de la dona i la menor estranyesa i l'acceptació social davant les crisis, ruptures i relacions extramatrimonials facilitades per l'existència d'anticonceptius. Barcelona, Madrid i València ocupen els ptimers llocs quant a nombre de causes de separació. ${ }^{13}$

Hi ha dos procediments per aconseguir eclesiàsticament la separació. L'un, sumari, en què les parts expressen que la «vida en comú és massa difícil» $\mathrm{i}$ després de la pertinent aportació de testimonis i d'un conveni signat per ambdues, en el qual es preveu la regulació dels efectes civils de la separació («fills, domicili, règim econòmic»), es dicta la pertinent resolució. L'altre consisteix en un procés pròpiament judicial amb la corresponent demanda acusatòria contra el cònjuge que el que inicià la causa considera culpable, amb la possible resposta i acusació per part d'aquest, aportació de proves sòlides i les pertinents defenses. Després d'aquests tràmits, el jutge dicta sentència, que és apellable.

f) Nova convivència, a desgrat del manteniment del vincle juridic, amb una altra persona diferent d'aquella amb la qual s'ba contret matrimoni. A desgrat de les separacions indicades en els apartats $d$ ) i $e$ ) que no permeten legalment noves convivències amb terceres persones, és força normal que els esposos que han trencat la vida en comú s'uneixin, amb una certa permanència $\mathrm{i}$ al marge de les normes legals, amb una altra persona. És una prova més de la crisi matrimonial i de la poca importància que algunes persones concedeixen als pactes $i$ a les resolucions judicials.

Peré Raluy intenta una aproximació al nombre de separacions de fet a les quals segueixen noves convivències, a través d'un estudi dels naixements inscrits durant un any en el Registre Civil de Barcelona, i escriu:

13. José Ma. Díaz Mozaz, op. cit., p. 23. 
«S'ha d'assenyalar que anulment s'inscriuen a Barcelona 50.000 naixements, dels quals corresponen als extramatrimonials uns 1.250 ; ara bé, d'aquestes xifres corresponen a fills de persones domiciliades a Barcelona ciutat sols un 70 per cent, cosa que suposa uns 35.000 nascuts de persones domiciliades a Barcelona, dels quals uns 875 són extramatrimonials. D'aquests 875 , uns 450 , aptoximadament, corresponen a unions estables en les quals, almenys, un dels progenitors és casat i separat de fet del seu cònjuge.

\Ja la simple circumstància que. les separacions de fet, després de produit-se, donin lloc, en les noves unions extramatrimonials formades pels cònjuges separats residents a Barcelona, a 450 naixements per any, indica el volum que assoleix el problema sobretot si es té en compte que no totes les separacions de fet donen lloc a uiteriors unions, ni que totes aquestes unions són fèrtils.

»Encara que és extremament aventurat tractar de deduir, del nombre de fills engendrats en les unions extramatrimonials dels còjuges separats de fet, el nombre de separacions de fet que es produeixen a Barcelona anualment, hi cap un intent d'aproximació a la realitat seguint el següent mètode. El nombre d'unions de fet una part de les quals és cònjuge separat pot calcular-se grosso modo establint una proporcionalitat entre matrimo* nis $i$ fills matrimonials per una part $i$ entre fills extramatrimonials engendrats en les relacions d'amistançament dels separats de fet $i$ el nombre d'aquestes. Per tant, es pot assenyalar que el nombre de matrimonis celebrats anualment a Barcelona és d'uns $12.000 \mathrm{i}$ que la fertilitat de les unions estables extramatrimonials pot xifrar-se en un terç de les matrimonials tenint en compte que si bé no falten unions extramatrimonials amb dos, tres $i$ més fills - $n$ 'hi ha amb vuit i deu-, és el més corrent que aquesta família sigui més reduida que la matrimonial i sigui major el nombre de concubinats estèrils que el de matrimonis sense fills; establint, doncs, la proporció $34.125 / 12.000=450 / X$, obtenim un valor de $X$, de 165 , i multiplicant-lo pel coeficient 3 de relació entre una i altra fertilitat ens dóna com a resultat un total de formació anual d'unes 500 unions extramatri. monials estables de separats de fet. No crec que el percentatge d'ertor d'aquest càlcul passi d'un $20 \%$; per tant, el nombre de tals unions que es formen per any deu oscillar entre 400 i $600 .{ }^{14}$

14. José Peré Raluy, «Aproximación estadística a las separaciones matrimoniales de hecho en Barcelonas, Sociologia y Psicologia juridicas (Anuario 1974), Ilustre Colegio de Abogados, p. 189. 
«Papers»: Revista de Sociologia

g) Assoliment d'una resolució judicial de divorci vincular amb dret a un nou matrimoni. No considerem oportú entrar a fons en les quiestions plantejades a favor o en contra del divorci vincular que té com a efecte la ruptura del liggam matrimonial. Implica una problemàtica molt complexa. A més, pel seu caràcter entenem que supera l'àmbit d'un article bàsicament sociològic $i$ forçosament limitat com el present.

Només considerem imprescindible afirmar que l'Església catòlica manté el seu criteri, ja tradicional, sobre la impossibilitat de la ruptura del vincle matrimonial en els casos de tratrimonis contrets amb la seva intervenció, i que al costat dels que sostenen que la unió merament civil és també indissoluble, existeix una tendència mantinguda per molts en el sentit d'admetre el divorci vincular pels qui s'han casat al marge de la vida eclesiàstica.

L'argument dels divorcistes radicals se sintetitza en les paraules de Goode: «No es pot obligar la gent perquè sigui feliç en el seu matrimoni; i si no s'és feliç no se la pot obligar a conviure. En realitat no significa més que un reajustament. $\rangle^{\text {is }}$

Els adversaris d'aquesta tesi, acceptada actualment en quasi tots els paisos, afirmen per la seva part que el divorci vincular és una poligàmia successiva o també «una poligàmia per etapes», com expressa Hunt. ${ }^{16}$

$\mathrm{Cal}$ recordar que únicament regeix el règim de no-admissió del divorci vincular en els següents països del món occidental: Itlanda, Malta, Argentina, Brasil, Xile, Colòmbia i Paraguai."

Quant a Espanya, cal tenir en compte que la Constitució aprovada per les Corts el dia 31 d'octubre de 1978, que obtingué el vot afirmatiu del poble en el Referèndum del dia 6 de desembre i fou promulgada el dia 29 de desembre del mateix any, preveu en l'article 32 el següent: «1. L'home i la dona tenen dret a contraure matrimoni amb piena igualtat jurídica. 2. La llei regularà les formes de matrimoni, l'edat i la capacitat per contreure'l, els drets i els deures dels cònjuges, les causes de separació i dissolució $i$ els seus efectes.» Acceptat el principi de la dissolució, cal esperar la llei especial que la reguli. Actualment, per tant, no és possible el divorci que signifiqui la ruptura matrimonial amb tots els efectes.

A Espanya, com és sabut, estigué vigent la llei de divorci promulgada durant la República el dia 12 de març de 1932 (Gaceta de Madrid del

15. Isidoro Alonso Hinojal, Lo crisis de la institución matrimonial (Barcelona: Saivat, 1974), p. 16.

16. Morton Kunt, op. cit., p. 286.

17. Vicente Luis Simó Santonja, Divorcio y separacion. Derecbo comparado y consultividad europea (Madrid: Tecnos, 1973). 
dia 12 del mateix mes) que regí des d'aquesta data fins al 31 de març de 1939 en la que fou zona republicana durant la Guerra Civil, i que va ésser derogada pocs dies després del «Alzamiento» en la zona anomenada «nacional».

En l'article 43 de la Llei fonamental tepublicana s'establia el següent: «La família està sota la salvaguarda especial de l'Estat. El matrimoni es fonamenta en la igualtat de drets per a l'un i l'altre sexe i podrà dissoldre's, per mutu dissens o a petició de qualsevol dels cònjuges, amb allegació, en aquest cas de justa causa.»

La \lei especial, en el seu article primer fixava el següent: «EI divorci decretat ferm pels tribunals civils dissol el matrimoni, qualsevol que hagi estat la forma i la data de la seva celebració.» I en l'article segon: «Hi haurà lloc al divorci quan ho demanin ambdós cònjuges de comú acord, o un d'ells en alguna de les causes determinades en aquesta llei sempre amb subjecció al que en ella es disposa.» ${ }^{18}$

En l'article tercer assenyalava les causes de divorci, comprenent les citades a continuació: «1a. L'adulteri no consentit o no facilitat pel cònjuge que l'allegui. 2a. La bigàmia, sense perjudici de l'acció de nullitat que pugui exercitar qualsevol dels cònjuges. 3a. La temptativa del marit per prostituir la seva dona i l'intent del marit o de la dona per corrompre els seus fills o prostituir les seves filles i la connivència en la seva corrupció o prostitució. 4a. El desempar de la família sense justificació. 5a. L'abandó culpable del cònjuge durant un any. 6a. L'absència del cònjuge quan hagin transcorregut dos anys des de la data de la seva declaració judicial, computada conforme a l'article 186 de. C.c. 7a. Atemptat d'un conjuge contta la vida de l'altre, dels fills comuns o dels d'un d'aquells; els maitractaments d'obra $\mathrm{i}$ les injúries greus, la violació d'algun dels detrres que imposa el matrimoni i la conducta immoral i deshontosa d'un dels cònjuges que produeixi una tal pertorbació a les relacions matrimonials, que facin insuportable per a l'altre cònjuge la continuació de la vida en cornú. 9 a. La malaltia contagiosa $i$ greu de caràcter veneri, contreta en relacions sexuals fora del matrimoni i després de la seva celebració, i la contreta abans, que hagi estat ocultada cuiposament a l'altre cònjuge a temps de celebrar-lo. 10a. La malaltia de la qual per presumpció raonable hagi d'esperar-se que en el seu desenvolupament produeixi incapacitat definitiva per al compliment d'alguns dels deures matrimonials, i la contagiosa, contretes ambdues abans del matrimoni i culposament ocuitades al temps de celebrar-lo.

18. José Rimblas Rimblas, Legislacion española de divorcio (Barcelona: Bosch, 1932), p. $16 \%$. 
11a. La condemna del cònjuge a pena de ptivació de llibertat per temps superior a deu anys. 12a. La separació de fet $\mathrm{i}$ en distint domicili, lliurement consentida, durant tres anys. 13a. L'alienació mental d'un dels cònjuges quan impedeixi la seva convivència espiritual en termes greument perjudicials per a la famúlia i que exclogui tota presumpció racional que aquella pugui restablir-se definitivament. No podrà decretar-se el divorci en virtut d'aquesta causa, si no queda assegurada l'assistència del malalt.»

Les causes invocades principalment per al divorci en aquest període foren les que segueixen: separació de més de tres anys $(20,72 \%)$, violació de deures $i$ conducta immoral (15,79\%), abandó $(15,78 \%)$, desempar de la família $(15,04 \%)$, mals tractes $(12,93 \%)$ i adulteri $(10,23 \%) .{ }^{19}$

En línies generals es pot indicar que les causes de divorci previstes en la major part de paüsos són les següents: adulteri, mals tractes, injúries, abandó de famólia, condemna penal, malaltia mental, separació de fet, atemptat contra la vida de l'altre cònjuge, malalties contagioses i tepulsives, proposició per a prostituir la dona, la bigàmia, la falta d'assistència familiar, la conversió de la separació en divorci, el mutu consentiment. ${ }^{20}$

Com a causes admeses en alguns països, es poden assenyalar: l'alcoholisme i l'embriaguesa, l'abús de drogues, la corrupció deis fills, la prostitució de les filles, embaràs anterior de la dona no causat pel marit, la impotència anterior $i$ continuada, l'aberració sexual en les seves diverses varietats, el vici del joc, la vida $\mathrm{i}$ costums deshonestos, la incompatibilitat d'humor o de caràcter, la crueltat mental, la violació, la falta de consumació del matrimoni, la mort presumpta, el rebutjar la procreació, la lepra, la intemperància habitual, la difamació pública, l'adhesió a una religió que exigeixi la renúncia al matrimoni i a la cohabitació, la vida vagarosa del marit, la prostitució de la dona anterior al matrimoni, l'incest, la dissipació de la propietat familiar, el divorci d'un dels esposos, obtingut a l'estranger, les pràctiques anticonceptives, i l'existència d'una causa no especificada, en Ia qual cap tot allò que provoca la inestabilitat i el desenvolupament normal del matrimoni.

En els últims anys, el divorci vincular ha tingut increments extraotdinaris. García Cantero ho posa en relleu: ${ }^{2 t}$

19. Inés Alberdi, Historia y Sociologia del divorcio en España (Madrid: Centro de Investigaciones Sociológicas, 1979), p. 103.

20. Vicente Luis Simó Santonja, El dato del divorcio en la sociedad occidental, dins El divorcio, problema bumano (Madrid: Karpos, 1976), p. 30.

21. Gabriel Garcia Cantero, El divorcio (Madrid: BAC, MCMLXXVII), p. 91. 
Gran Bretanya (1962-1974): $438 \%$.

Holanda (1962-1974): $235 \%$.

Dinamarca (1964-1974): $400 \%$.

Polònia (1950-1970): $300 \%$.

Canadà (1968-1974): $300 \%$.

Bèlgica (1960-1974): $200 \%$.

República Federal Alemanya (1960-1973): $250 \%$.

Suissa (1960-1974): $200 \%$.

Dinamatca (1968-1974): $200 \%$.

Finlàndia (1969-1975): $200 \%$.

República Democtàtica Alemanya (1960-1974): $200 \%$.

Cuba (1968-1973): $200 \%$.

República Dominicana (1970-1972): $200 \%$.

EUA (1950-1974): quasi el $200 \%$. En pocs anys, ha passat del 23,42\% al $43,89 \%$.

h) Assoliment d'una sentència judicial, en què es declara nulla la unió matrimonial, o d'una dispensa que deixa sense efecte el matrimoni. En ambdós casos es reconeix l'estat de solteria $i$, per tant, la possibilitat de contraure un nou enllaç. En el primer cas, s'aconsegueix, per la via civil o exlesiàstica, una sentència judicial que declara inexistent el matrimoni, perquè han faltat requisits o condicions bàsiques per a la seva validesa. En el segon, l'Església catòlica declara sense efecte les unions en les quals no s'ha consumat el matrimoni.

Són poques, en el nostre paús, les nullitats obtingudes a través de la jurisdicció civil, ja que, encara que han augmentat en els últims anys, és molt limitat el nombre de matrimonis contrets davant els Jutiats no ecle. siàstics.

En l'àmbit de l'Església, són causes de nullitat —citem les més importants - les següents: la incapacitat intellectual per a comprendre el que és el matrimoni; la manca de la libertat $i$ altres vicis del consentiment; la impotència anterior $i$ perpètua per a l'acte sexual; greus anomalies psíquiques i sexuals; una o diverses de les següents exclusions: de la unitat, de la indissolubilitat, del Sagrament i dels fills.

Naturalment, totes aquestes causes han d'haver existit abans de «contraure» matrimoni.

En els darrers temps, a conseqüència, en bona part, del Concili Vaticà II, existeix una tendència entre els tractadistes i la Jurisprudència a considerar la manca d'amor previ al matrimoni. Per a alguns, el fet de l'amor conjugal no té cap importància juridica; altres tracten de considerar-lo com un fi essencial del matrimoni, aitres el tenen corn un element 
constitutiu del consentiment $i$ per a altres és un objecte essencial del consentiment matrimonial.

Alguns autors consideren que cal revisar el dogmatisme jurídic que obliga a afertar-se a fórmules fetes i que, en canvi, cal investigar en la realitat de la vida matrimonial per, entre tots, anar clarificant idees $i$ acomodant en cada moment el Dret a la realitat existencial. Que és necessari revisar la doctrina contractualista del matrimoni i elaborar una teoria personalista d'aquest partint dels pressuposits del Concili Vaticà II $i$, en concret de la realitat de l'amor conjugai i de la intimitat de vida que aquest crea, mantenint-se la fidelitat als principis essencials del cristianisme.

L'Església catòlica, com és sabut, concedeix excepcionalment i amb justa causa algunes dispenses que deixen sense efecte el matrimoni. La més coneguda és la de «matrimoni rat i no consumat», que respon a l'antiga concepció segons la qual el matrimoni, essent vàlid, no està totalment perfeccionat si too s'ha arribat a la unió sexual completa.

En els últims anys s'han incrementat intensament les demandes $i$ sentències de nullitat de matrimoni. A continuació indiquem el nombre de causes introduïdes, de declaració de nullitat i denegades en diversos anys: ${ }^{22}$

\begin{tabular}{lcccc}
\hline Any & $\begin{array}{c}\text { Causes } \\
\text { introdüdes }\end{array}$ & $\begin{array}{c}\text { Sentències } \\
\text { favorables }\end{array}$ & Denegades & $\begin{array}{c}\text { Andex de creixement } \\
\text { de les causes introduides }\end{array}$ \\
\hline 1952 & 81 & 31 & 22 & 100 \\
1956 & 79 & 27 & 16 & 75 \\
1960 & 88 & 32 & 18 & 108,6 \\
1965 & 81 & 24 & 14 & 100 \\
1970 & 176 & 115 & 22 & 217,2 \\
1974 & 375 & 167 & 30 & 464 \\
\hline
\end{tabular}

Manquen les dades corresponents a Canàries dels anys 1960, 1965 i 1974; les de Tuy-Vigo de l'any 1965 i de Granada, València i Valladolid de l'any 1974.

22. José Ma. Díaz Mozaz, op. cit., p. 169. 
Conflictivitat i ruptura en el matrimoni

Referint-nos al Tribunal de Barcetona, hi incloem les següents dades: ${ }^{23}$

\begin{tabular}{cccc}
\hline Any & Introduites & Sentencies & Arxivades \\
\hline 1960 & 15 & 19 & - \\
1961 & 18 & 25 & 11 \\
1962 & 19 & 12 & 6 \\
1963 & 23 & 15 & 10 \\
1964 & 16 & 11 & 3 \\
1965 & 18 & 16 & 3 \\
1966 & 20 & 14 & 4 \\
1967 & 16 & 10 & 7 \\
1968 & 25 & 13 & 8 \\
1969 & 32 & 16 & 14 \\
1970 & 38 & 16 & 12 \\
1971 & 33 & 13 & 8 \\
1972 & 59 & 26 & 22 \\
1973 & 59 & 26 & 21 \\
1974 & 102 & 27 & 24 \\
1975 & 197 & 40 & 26 \\
1976 & 357 & 60 & 44 \\
1977 & 298 & 100 & 65 \\
1978 & 224 & 120 & 27 \\
\hline
\end{tabular}

L'increment en les causes de nullitat introdüdes ha estat extraordinari. Amb una base 100 per a l'any 1960 , el 1978 s'arriba al $1.426 \%$. Quant a les sentències, l'augment és del $631,5 \%$.

Estudi de causes de separació tramitades en el Tribunal Eclesiàstic de Barcelona

Gràcies a l'amabilitat i a les facilitats donades pel Tribunal Eclesiàstic, hem pogut aconseguir unes dades que es refereixen al nombre de separacions que s'han iniciat en el dit Tribunal i que afecten l'àmbit de l'Arxi. diòcesi de Barcelona.

23. Dades facilitades pel Tribunal Eclesiàstic de Barcelona. 
«Papers»: Revista de Sociologia

Del període de 1960 a 1974 , en què es tramitaren 6.301 causes, s'ha pogut examinar una mostra de 769 casos, que representa un $12,2 \%$ de les causes tramitades.

Examinats els dubios, o sigui la diligència processal en la qual es fixen d'una forma concreta els motitus de la separació o, en el seu cas, de nullitat, per part del Tribunal, d'acord amb les parts, es pot presentas el segitent quadre sobre les causes allegades. Comprèn del 1960 al $1972 .^{24}$

\begin{tabular}{|c|c|c|}
\hline Causes & Total & Percentatges \\
\hline AduIteri $\ldots \ldots \ldots \ldots \ldots \ldots$ & 113 & 17,4 \\
\hline Sevícies $\ldots \ldots \ldots \ldots \ldots \ldots$ & 239 & 30,0 \\
\hline Sevícies $\mathrm{i}$ adulteri $\ldots . . .$. & 158 & 20,3 \\
\hline Abandó $\ldots \ldots \ldots \ldots \ldots$ & 99 & 12,7 \\
\hline Sevícies i abandó ........ & 138 & 17,4 \\
\hline Anomalies sexuals ..... & 22 & 2,2 \\
\hline
\end{tabular}

Per dificultats de la tabulació, degudes en bona part a la forma en què han estat emplenades les fitxes que s'han utilitzat, als efectes del que s'indicarà a continuació, s'ha extret una submostra de 243 casos, corresponents als anys 1960,1965, 1968, 1970 i 1972, escollits a l'atzar.

En aquesta submostra s'examinen les variants segiients:

Iniciativa de la separació segons sexe, edat en què es va contraure el matrimoni, nombre de fills, $i$ anys de convivència.

Iniciativa de la separació segons sexe

\begin{tabular}{|c|c|c|}
\hline & Homes & Dones \\
\hline Nombre de casos ........ & 47 & 196 \\
\hline Percentatge.......$\ldots \ldots$ & $18,9 \%$ & $81,1 \%$ \\
\hline
\end{tabular}

24. Dades facilitades pel Tribunal Eclesiàstic de Barcelona. 
Segons el quadre anterior, en el $81,1 \%$ dels casos la sollicitud ha estat presentada per la dona, la qual cosa indica, una vegada més, la importància que per a aquesta té la institució matrimonial $i$ com li afecta tot el que hi fa teferència.

Edat en què es va contraute el matrimoni

\begin{tabular}{cccccc}
\hline Anys & $18-21$ & $22-26$ & $27-30$ & 31.34 & +35 \\
\hline Nombre de casos $\ldots . .$. & 90 & 81 & 46 & 12 & 18 \\
Percentatge $\ldots \ldots . . . .$. & $37 \%$ & $33 \%$ & $18 \%$ & $5 \%$ & $7 \%$ \\
\hline
\end{tabular}

En aquesta submostra es posa en relleu que els matrimonis es contrauen entre els $18 \mathrm{i}$ els 26 anys. Aquest fet ens pot portar a considerar si els matrimonis contrets per persones molt joves tenen menys solidesa, a causa de la manca de maduresa sòcio emocional dels contraents, sense que això es pugui demostrar estadísticament per insuficiència de dades. A part que no sempre corresponen l'edat psíquica amb l'edat cronològica.

Nombre de fills en el matrimoni

\begin{tabular}{|c|c|c|c|c|c|c|}
\hline Nombre de fills & 0 & 1 & 2 & 3 & 4 & +4 \\
\hline Nombre de casos. & 57 & 66 & 67 & 18 & 12 & 14 \\
\hline Percentatge ...... & $23,4 \%$ & $27,1 \%$ & $27,5 \%$ & $11,5 \%$ & $4,9 \%$ & $5,6 \%$ \\
\hline
\end{tabular}

Es dedueix que hi ha un major nombre de separacions entre els ma. trimonis sense fills o amb un màxim de dos, que entre aquells que en tenen més de tres. D'això no podem deduir que el nombre de fills sigui indicador de la conflictivitat ni que hi hagi menys discordances entre els pares de nombrosos fills. El que sí que es pot afirnar és que l'existència d'aquests, amb les atencions afectives $i$ econòmiques que comporten, $\mathfrak{f a}$ en moits casos que les tensions passin a segon terme.

Això és, una vegada més, exponent de la dependència en què es troba la dona en el matrimoni, de cara a fer front a l'educació i a la sub. sistència dels fills. Hem vist que, en un $81 \%$ de les demandes, la inicia- 
tiva havia partit de la dona, i s'observa que els matrimonis sense fills $o$ amb un màxim de dos, suposen precisament un $78 \%$ del total, xifra que coincideix significativament amb la de la iniciativa en la demanda de separació per part de les dones.

Anys de convivència

\begin{tabular}{cccccc}
\hline Periodes d'anys & $1-3$ & $3-6$ & $6-10$ & $10-15$ & +15 \\
\hline Nombre de casos ..... & 46 & 42 & 60 & 49 & 46 \\
Percentatge $\ldots . . . \ldots . .$. & $19,3 \%$ & $17,2 \%$ & $24,6 \%$ & $20,1 \%$ & $18,8 \%$ \\
\hline
\end{tabular}

Observant aquest quadre, en el qual hem establert uns intervals d'anys segons la duració de la convivència, constatem, en primer lloc, que el vèrtex de ruptura s'estableix en l'interval de 6 a 10 anys de matrimoni (un $24,6 \%$ ), és a dir, en aquells que el van contraure entre els 18 i els 26 anys (el $80 \%$, com hem vist).

Considerant que aquest vèrtex supera en un $10 \%$ el percentatge dels períodes anterior i posterior, podem dir que la població femenina (un $81 \%$ de les demandes) sembla adquirir consciència de la seva situació d'inferioritat respecte a la seva parella en aquesta etapa de la seva vida conjugal.

És en aquest petíode, si l'experiència no ha estat positiva, quan la dona fa front al seu problema a fi de no bipotecar el seu desenvolupament com a persona humana.

\section{Realitats $i$ perspectives}

No pretenem, ni considerem adequat, fixar unes conclusions en acabar el present trebail. Tan sols volem constatar, en forma sintètica i breu, els fets que han estat examinats en les ratlles anteriors, que es donen en la realitat social del que anomenem món occidental.

L'existència i l'augment de crisis matrimonials és molt més nombrós i generalitzat del que les aparences semblen demostrar. Els convencionalismes socials, la temença de trobar-se en situacions pitjots, $i$ una hipocresia que intenta dissimular-les, fan que el problema no sigui conegut en tota la seva dimensió i gravetat. 
Sens dubte, són moltes les causes que porten a aquesta situació. Intentar analitzar-les, portaria a una tasca complexa i llarga. Només volem afirmar que el materialisme egoista, la massificació i el consumisme característics de la societat capitalista són, en bona part, causa de la situació plantejada.

La conseqüència més directa, visible i greu, juntament amb la infelicitat i el sofriment dels afectats, es troba en la proliferació cada dia més abundant dels divorcis $\mathrm{i}$ de les nullitats de matrimoni, que no poden ésser considerats, molt sovint, com una solució perfecta i definitiva, sinó com una sortida d'unes circumstàncies socials que s'han fet insuportables.

En els temps moderns es destaca en el matrimoni, sense perjudici de la seva valoració jurídica, religiosa i social, la necessitat de l'existència d'un veritable amor psiquic $i$ sexual, i d'una compenetració intellectual i afectiva.

Aquesta consideració més valuosa que es dóna a l'amor, per damunt de la mera sexualitat i al marge de l'interès econòmic o el prestigi social, significa un notable avenç.

Cal tenir en compte que en el passat, i encara actualment en molts paisos $i$ àmbits socials, els enllaços matrimonials eren $\mathrm{i}$ són efecte de la pressió, i fins de la imposició de tercers sobre les idees, els sentiments i la voluntat dels contraents.

Caldrà veure si les formes d'unió personal i sexual —el matrimoni de «doble carrera», les unions de fet, l'open mariage, les comunes, el matrimoni de grup, etc. $\rightarrow$ signifiquen formes de certa permanència i continuitat, en les quals l'amor prevalgui.

En fi, està estès el criteri que a un consentiment conscient, lliure $i$ responsable, com a element fonamental de la relació que es constitueix, cal unir l'amor, que és l'element més important de la comunitat que es crea i és, a la vegada, condició perfecta i meta òptima dels cònjuges.

Seguidament s'insereix un mapa d'Espanya, reprodüt del llibre Curso de Derecho matrimonial y procesal canónico para profesionales del foro. Ponencias del IV Simposio de Miembros de Tribunales Eclesiásticos, Saiamanca, Universidad Pontificia, 1977, com a complement de la Ponència Datos sociológicos y estadisticos de la actual crisis matrimonial, que estigué a càrrec de José M. Díaz Mozaz.

EI mapa reflecteix el fet que les diòcesis de major població, industrialització o objecte del turisme, són les que tenen un més gran nombre de catses matrimonials (separacions i nullitats) introduides en els Tribunals Eclesiàstics durant l'any 1974. 
«Papers»: Revista de Sociologia

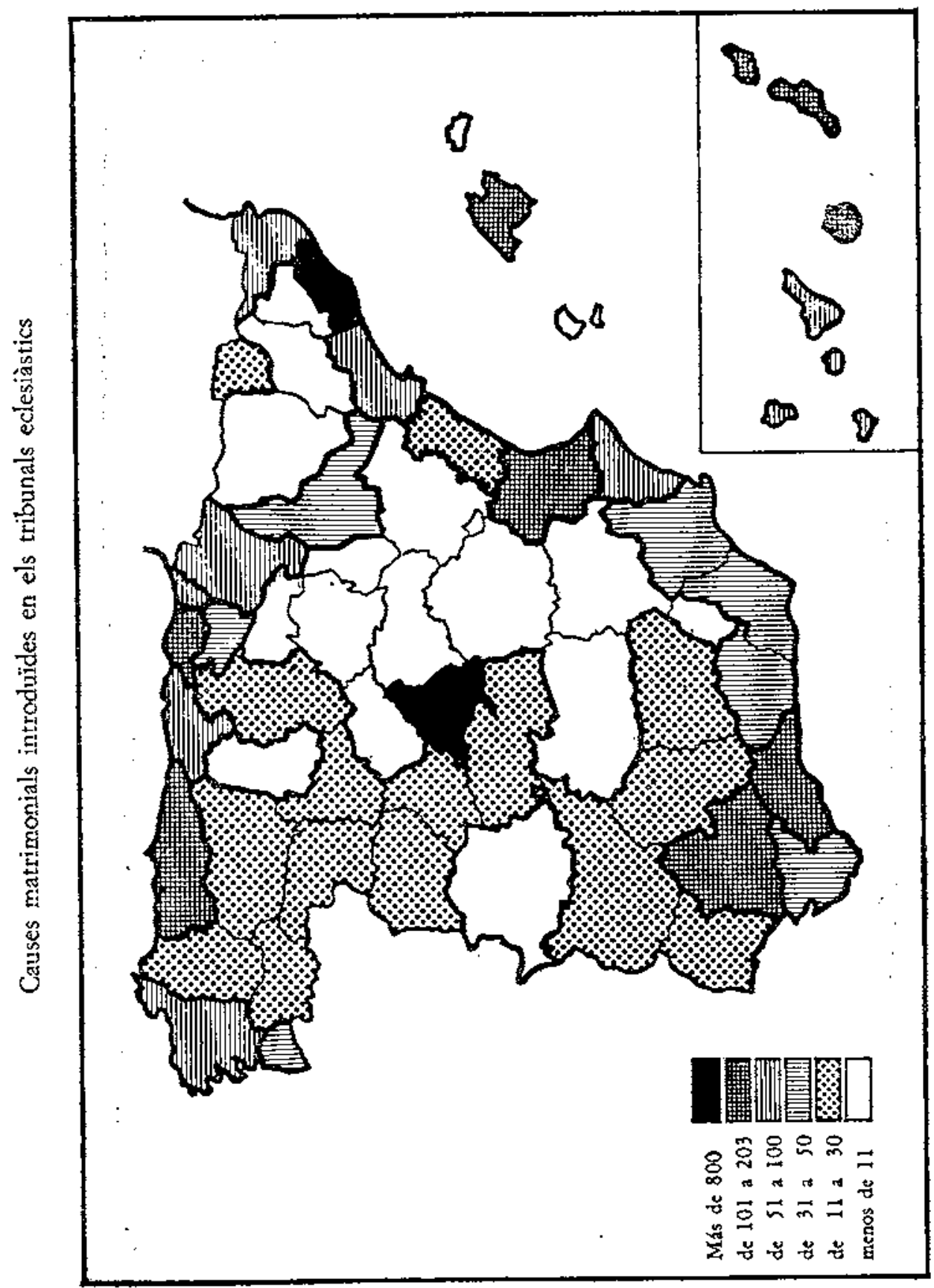

